\title{
The role of acute respiratory infections in the pathogenesis of distal limb infections in cattle
}

\author{
A.D. Alekseev ${ }^{1,}$, O.G. Petrova ${ }^{1}$, M.I. Barashkin ${ }^{1}$, I.M. Milstein ${ }^{1}$, and N.M. Kolobkova ${ }^{2}$ \\ ${ }^{1}$ Ural State Agrarian University, Karla Libknehta str. ,42, 620072 Ekaterinburg, Russia \\ ${ }^{2}$ South Ural State Agrarian University, Gagarina str., 13, 457100 Chelyabinsk region, Troitsk, Russia
}

\begin{abstract}
Acute respiratory diseases of infectious etiology of cattle occupy the second place in the nosological picture after diseases of the digestive system and cause huge economic damage, which in the Russian Federation is estimated at several billion rubles annually. Very often, respiratory pathology in highly productive cows is associated with infections of the distal extremities, primarily with necrobacteriosis, streptococcosis and staphylococcosis, which cause significant economic damage by reducing the productivity of animals. An important pathogenetic factor affecting the development of diseases of the distal extremities in cattle (cattle) are infections of the respiratory tract. According to our long-term observations, all farms in which outbreaks of necrobacteriosis were recorded were unfavorable for respiratory infections of cattle, such as infectious rhinotracheitis (IRT), viral diarrhea (VD), parainfluenza type 3 (PG-3), respiratory syncytial infection (RSI), pasteurellosis, chlamydia, salmonellosis and others.
\end{abstract}

\section{Introduction}

According to our observations, in $25.4 \%$ of cows, respiratory pathology is associated with infections of the distal extremities, primarily with necrobacteriosis, streptococcosis and staphylococcosis, which cause economic damage by reducing the productivity of animals [1,2]

The starting factor affecting the development of distal limb infections in cattle is respiratory tract infections. Farms where outbreaks of necrobacteriosis were recorded were not successful in bovine respiratory infections, such as IRT, VD, PG-3, RSI, pasteurellosis, chlamydia, salmonellosis.

\section{Materials and methods}

The research was conducted at the Department of Infectious and Non-Infectious Pathology of the Ural State Agrarian University and agricultural Enterprises of the Ural region in the period 2014-2021. Pathomorphological, epizootic, immunological and bacteriological research methods were used.

\footnotetext{
${ }^{*}$ Corresponding author: alexeevbest@mail.ru
} 
The object of the study was cattle with industrial technologies of keeping, blood and blood serum of cattle, pathological material from a forced slaughtered fourteen-day-old calf - pieces of lung and bronchial lymph nodes, scrapings from the hooves of cattle.

To determine the epizootological situation for acute respiratory diseases, a statistical method was used - the reporting documents of the Information and Analytical Center of the Federal Service for Veterinary and Phytosanitary Surveillance Veterinary Supervision Department (FGBU "ARRIAH"), the reports of the Udmurt Veterinary Diagnostic Center, the Chelyabinsk Interregional Veterinary Laboratory, and the Sverdlovsk Interregional Veterinary Laboratory were studied.

The pathological material from the fallen calf was fixed in $10 \%$ formalin, filled with paraffin, and histological preparations were prepared according to the generally accepted method. The preparations were stained with hematoxylin and eosin, as well as by Van Gieson, after which they were studied by light microscopy according to the generally accepted method.

The blood of cows and calves was the material for hematological studies. To assess the circulating immune complexes in the blood serum, the method of immunoprecipitation in a $4 \%$ solution of polyethylene glycol (PEG-6000) was used, followed by photometry on a spectrophotometer SF-2000 (Russia).

Bacteriological studies were carried out according to generally accepted methods.

Digital data of epizootological and laboratory studies are processed by the methods of mathematical statistics adopted in biology and medicine. The reliability of the results was determined by statistical processing and determination of $\mathrm{M} \pm \mathrm{m}$, with the calculation of the arithmetic mean $\mathrm{M}$, the mean square deviation $\delta$, the error of the arithmetic mean $\mathrm{m}$, the average error of the indicator expressed as a percentage of $\mathrm{mp}$, using the Student's paired test $t$. The results were considered reliable at $\mathrm{P}<0.05$. To process the data obtained, we used the program "Microsoft Excel", which is included in the software package "Microsoft Office".

\section{Results and discussion}

Acute respiratory viral infections in the infectious pathology of cattle in the Urals occupy the second place after infectious diseases of the gastrointestinal tract[1]. The greatest spread of viral respiratory pathology was registered in the farms of the Udmurt Republic. The leading place in the unfavorable points is occupied by: in the Udmurt Republic: pasteurellosis-41.5\%, PG-3 (parainfluenza-3) - 16.7\%, chlamydia-14.1\%, VD (viral diarrhea) - 11.8\%, IRT (infectious rhinotracheitis) - $10.6 \%$, RSI (respiratory syncytial infection) $-5.4 \%[2,3]$.

In the Chelyabinsk region, pasteurellosis was detected-46.3\%, IRT-21.9\%, VD-12.2\%, chlamydia-7.3\%, PG-3-7.3\%, and RI-4.9\%. In the Sverdlovsk region, pasteurellosis $63.7 \%$, PG-3-14.9\%, VD-8.5\%, IRT-7.5\%, chlamydia-5.5\%.

Table 1. Percentage of dysfunctional agricultural enterprises for acute respiratory infections in cattle.

\begin{tabular}{|c|l|c|c|c|}
\hline № & Disease & Udmurt Republic, $\%$ & Chelyabinsk region, \% & Sverdlovsk region, \% \\
\hline 1. & Pasteurellosis & 41,5 & 46,3 & 63,7 \\
\hline 2. & Chlamydia & 14,1 & 7,3 & 5,5 \\
\hline 3. & PG-3 & 16,7 & 7,3 & 14,9 \\
\hline 4. & VD & 11,8 & 12,2 & 8,5 \\
\hline 5. & IRT & 10,6 & 21,9 & 7,5 \\
\hline 6. & RSI & 5,4 & 4,9 & - \\
\hline
\end{tabular}

The difference is significant. $\mathrm{P} \leq 0.05$. 
We estimated the prevalence of bovine respiratory syncytial infection in agricultural enterprises of the Ural region, so, in the Udmurt Republic, the RSI is $5.4 \%$ in the general pathology of ARVI, in the Chelyabinsk region - 4.9\%. In the Sverdlovsk region, according to the data of the Sverdlovsk Regional Veterinary Laboratory, RSI was not registered[4,5,15].

Serological, molecular-biological, microbiological and immunological studies indicate a wide participation of pathogens of different taxonomic groups in respiratory pathology. The most frequently identified associations of RSI with IRT, pasteurellosis, and other infectious agents: In the Udmurt Republic: RI + pasteurellosis + chlamydia-1.8\%; RSI + IRT + pasteurellosis-1.6\%; RSI + pasteurellosis-1.6\%; RSI + IRT + VD + pasteurellosis-1.5\%; RSI + IRT + pasteurellosis + chlamydia- $1.4 \%$; RSI + IRT + VD + pasteurellosis + chlamydia- $0.8 \%$; RSI + IRT + VD + chlamydia - 0.8\%; RSI + IRT + VD- $0.5 \%$; RSI + VD + pasteurellosis- $0.5 \%$; RSI + IRT + PG-3 + pasteurellosis- $0.4 \%$ (Table 2.3 )

Table 2. Viral and bacterial associations of BRSV in agricultural enterprises of the Udmurt Republic.

\begin{tabular}{|c|l|c|}
\hline$№$ & $\begin{array}{l}\text { Viral and bacterial associations of RSI in the Udmurt } \\
\text { Republic }\end{array}$ & $\begin{array}{c}\text { Percentage of the total number } \\
\text { of ARD-affected localities, \% }\end{array}$ \\
\hline 1. & RSI + pasteurellosis + chlamydia & 1,8 \\
\hline 2. & RSI + IRT + pasteurellosis & 1,6 \\
\hline 3. & RCI + pasteurellosis & 1,6 \\
\hline 4. & RSI + IRT + VD & 1,5 \\
\hline 5. & RSI + IRT + pasteurellosis + chlamydia & 1,4 \\
\hline 6. & RSI + IRT + VD + pasteurellosis + chlamydia & 0,8 \\
\hline 7. & RSI + IRT + VD + chlamydia & 0,8 \\
\hline 8. & RSI + IRT + VD & 0,5 \\
\hline 9. & RSI + VD + pasteurellosis & 0,5 \\
\hline 10. & RSI + IRT + PG-3 + pasteurellosis & 0,4 \\
\hline
\end{tabular}

The difference is significant. $\mathrm{P} \leq 0.05$.

In the Chelyabinsk region: RSI + IRT + pasterellez-4.9\%; RSI + IRT + WD + PG-3 + pasterellez + chlamydia- $2.4 \%$.

Table 3. Viral and bacterial BRSV association in the agricultural enterprises of the Chelyabinsk region.

\begin{tabular}{|l|l|c|}
\hline № & $\begin{array}{l}\text { Viral-bacterial associations of RSI in the Chelyabinsk } \\
\text { region }\end{array}$ & $\begin{array}{c}\text { Percentage of the total } \\
\text { number of ARD-affected } \\
\text { localities, \% }\end{array}$ \\
\hline 1. & RSI + IRT + pasteurellosis & 4,9 \\
\hline 2. & RSI + IRT + WD + PG-3 + pasteurellosis + chlamydia & 2,4 \\
\hline
\end{tabular}

The difference is significant. $\mathrm{P} \leq 0.05$.

In large dairy complexes, the frequency of RSI of cattle depended on the level of infection of animals with the cattle IRT virus and pasteurellosis, as well as the presence in herds of animals persistently infected with the respiratory syncytial virus, with the level of infection of animals with the cattle IRT virus from 10.6 to $21.9 \%$, pasteurellosis from $41.5 \%$ to $46.3 \%$ [5].

We have not found any differences in the geographical distribution of the disease among cattle of different ages. The largest number of seropositive to IRT, VD, RSI viruses and distal limb infections in animals was detected in large dairy farms with a high concentration and milk productivity of cows. The infection rate of cattle in medium and small farms was lower, but with an increase in milk productivity, it increased, and with it the risk of respiratory diseases occurring with the participation of this virus. The density of 
animals per unit area, as well as the introduction of virus carriers into the herd, was of great importance $[4,15]$.

The results of the studies proved that the spectrum of microorganisms that cause pathology of the respiratory system of cattle and diseases of the distal extremities is quite wide. Bacterial diseases are often secondary, but can occur as concomitant or independent. This depends on the concentration of animals, the presence or absence of specific prevention of viral and bacterial diseases, as well as economic factors. In this regard, when planning anti-epizootic measures, it is extremely necessary to conduct a full range of diagnostic studies (virological, bacteriological) in order to decipher the etiological structure of a particular outbreak of respiratory diseases and to clarify the etiological role of each infectious agent.

Conducted research in one of the livestock farms of the Chelyabinsk region from the fallen 14-day-old calf, pathological material was obtained - lung and bronchial lymph nodes.

Histological examination of the pathological material revealed signs of pneumonia characteristic of pasteurellosis (Fig. 1-2), and syncytia was found in the lung tissues, which is a diagnostic sign of RS in cattle [3, 4, 5] (Fig. 3-4).

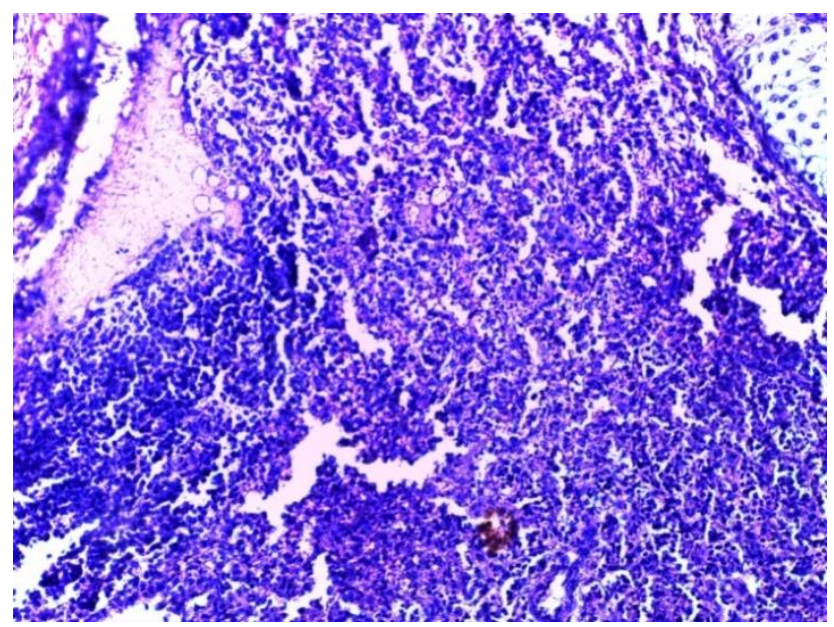

Fig. 1. Foci of purulent pneumonia. Staining with hematoxylin and eosin. Magnification 200.

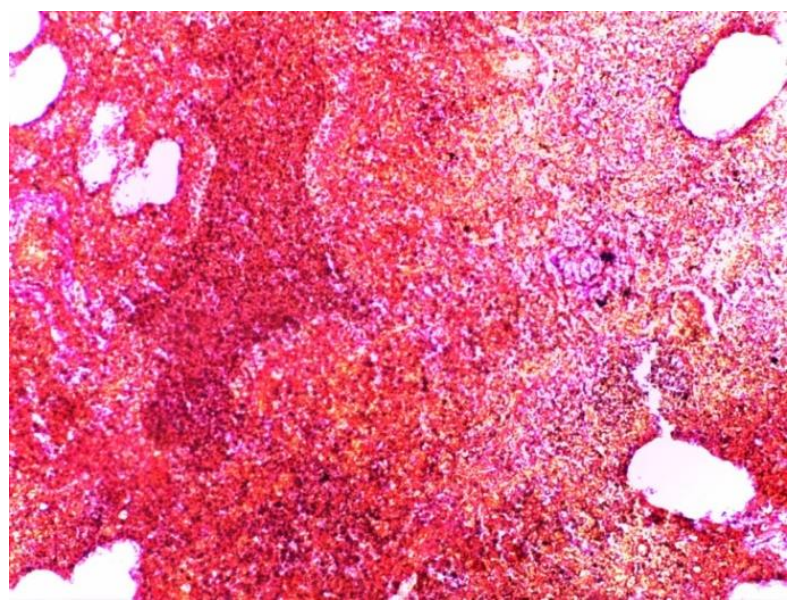

Fig. 2. Focal hemorrhagic pneumonia. Staining according to Van Gizon. Magnification 200. 


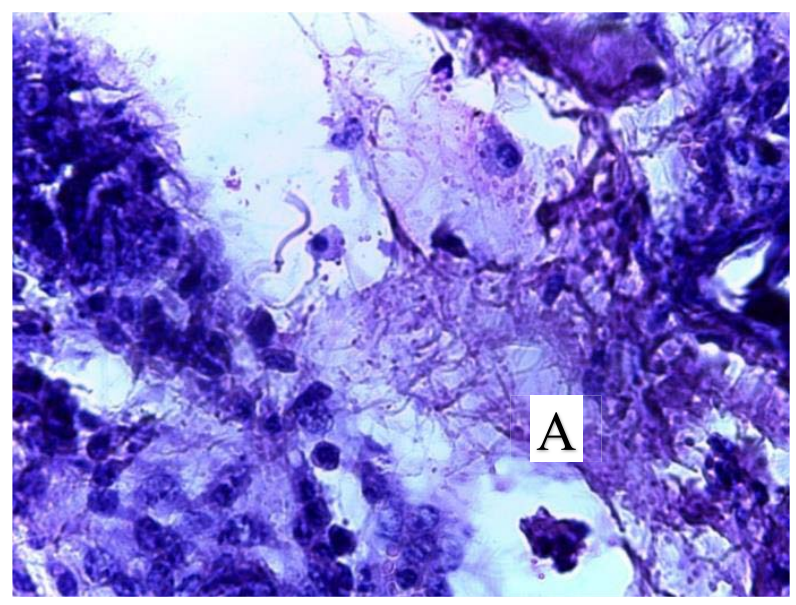

Fig. 3. Macrophages in the lung and syncytia (A), characteristic of respiratory syncytial infection. Staining with hematoxylin and eosin. Magnification 630.

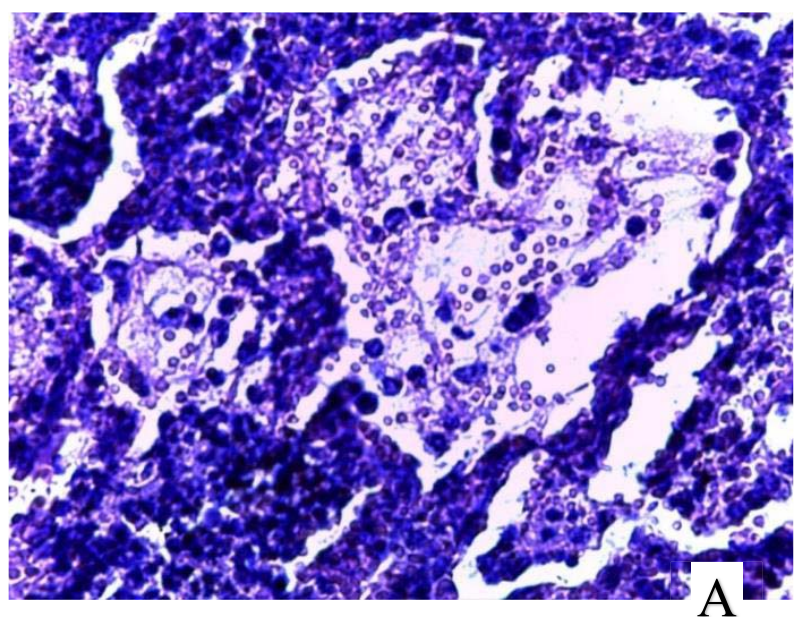

A

Fig. 4. Macrophages, erythrocytes and syncytia (A) in the lumen of the alveoli, characteristic of respiratory syncytial infection. Staining with hematoxylin and eosin. Magnification 400.

According to the results of the histological examination of the pathological material, the conclusion was made: the nature of the processes found in the studied preparations corresponds to the associated viral-bacterial infection RSI + pasteurellosis. $[3,4,5]$

Infectious pathology of the distal extremities was noted in the farm, and Fusobacterium necrophorum was isolated from the hooves of cows during bacteriological examination of the pathological material.

Thus, the farm registered a problem with acute respiratory diseases of infectious etiology (RI+pasteurellosis) in association with a wound infection of the distal extremities (necrobacteriosis).

We studied the concentration of CEC in the blood of deep-bedded cows 2 months before calving and 30-day-old calves (Table 4).

Table 4. Concentration of circulating immune complexes in the blood of cows and calves.

\begin{tabular}{|l|c|c|}
\hline Indicator & Cows $(\mathrm{n}=10)$ & Calves $(\mathrm{n}=10)$ \\
\hline CEC, cu. & $212,400 \pm 0,645$ & $234,460 \pm 5,905$ \\
\hline
\end{tabular}


As can be seen from Table 1, the concentration of CEC in cows and calves was higher than the physiological norm.

We found that acute respiratory infections are an important pathogenetic factor in the development of wound infections of the distal extremities of cattle.

According to modern concepts, rumen acidosis and metabolic acidosis are the result of feeding cattle mainly with canned acidic feed, such as silage and haylage $[5,6,7,8,9,10]$. Many cellulolytic bacteria (Ruminococcus, etc.) and fungi (Neocallimasticaceae family) are also sensitive to acidification of the environment. When their growth is inhibited, the cellulase activity of the contents of the scar decreases. The gastrointestinal tract of the cow stops digesting fiber, and the absorption of the diet is sharply reduced. In the next stage, the acidified environment inhibits the bacterium that started this process. Streptococcus bovis is replaced by lactic acid bacteria of the genus Lactobacillus, which are more resistant to acidic environments ( $\mathrm{pH}$ is lower).Under such conditions, a dangerous bacterium Fusobacterium necrophorum appears in the rumen, which can penetrate through the rumen wall into the blood, as well as other microorganisms capable of synthesizing toxins at the same time, so errors in feeding are not the only etiological factor leading to acidosis, since a number of authors have found that respiratory pathology is observed against the background of acidosis in cattle, caused by viral and bacterial microorganisms $[8,9,11,12]$.

The main pathological factor caused by acute respiratory infections in cattle are bronchitis, tracheitis

and pneumonia. When the respiratory tract is affected, hypoxia occurs in the body of animals, which leads to the occurrence of endogenous intoxication, leading to rumen acidosis $[11,12]$. As a result of acidosis, vasoactive substances (bacterial endotoxins, histamine, lactate) enter the bloodstream) $[7,8,9,10]$, due to the simultaneous expansion of arterioles and compression of venules, the vascular endothelium is damaged, blood fluid is perfused from the vessels into the surrounding tissues, and blood flow in the microcirculatory bed is disrupted [7].

An important role in the violation of blood circulation in small blood vessels is played by circulating immune complexes (CIC), which are a complex of "antigen-antibody". The formation of CEC is one of the factors of the normal response of the body's immune system to the introduction of the pathogen. At the same time, an increased concentration of CEC, which occurs with a large antigenic load on the body or with a violation of the mechanisms of elimination of CEC from the body, leads to pathological changes in the tissues and organs of animals, which is due to the high biological activity of CEC. Most CCS are rapidly removed from the circulating blood due to the reticulohistiocytic system, which combines various heterogeneous groups of cells in the body, in particular Kupffer cells, capable of active phagocytosis. CICS have both immunostimulating and immunosuppressive properties. The most pathogenic are CICS that can activate the complement system and react with blood cells that have receptors for binding immunoglobulins or complement. The main mechanism of the damaging action of CEC is complement-and neutrophil-dependent. CEC associated with complement exhibit chemotactic properties, which leads to the accumulation of neutrophils in the lesions and the release of hydrolytic enzymes that destroy the body's tissues. However, CEC can also cause pathology regardless of the presence of neutrophils and complement [13]. Small CICS can accumulate in various organs and tissues, cause inflammation and damage to biological structures. More often, immune complexes are deposited in the endothelium of blood vessels, renal glomeruli, and joints, which, accordingly, is manifested by clinical signs of joint disease [14].

In cattle, the vessels of the distal extremities are primarily affected, which leads to a violation of the trophic skin of the limbs and hooves, laminitis develops, while the hoof horn is weakly keratinized and cannot resist aggressive mechanical and chemical 
environmental factors[7, 10]. Damaged hooves are the gateway to infection for the pathogens of necrobacteriosis Fusobacterium necrophorum, Staphylococcus staphylococcus spp., Streptococcus streptococcus spp. and other pathogens [7, 10, 12, 15]. In addition, favorable conditions for the development of mixed infection are created by reducing the overall resistance of the body, which is noted both in respiratory pathology and in pathology of the distal extremities [15].

\section{Conclusion}

As our studies have shown, the primary cause contributing to the development of distal limb infections in cattle is metabolic acidosis, with a decrease in the natural resistance of the body with the occurrence of respiratory infections against this background. According to our long-term observations, all farms in which outbreaks of necrobacteriosis were recorded were unfavorable for respiratory infections of cattle, such as IRT, VD, PG-3 and RSI.

Comprehensive prevention of infections of the distal extremities of cattle should include mandatory laboratory diagnostics of acute respiratory diseases.

\section{References}

1. Yu.N. Alyokhin, M.S. Zhukov, A.Yu. Lebedeva, Veterinary medicine, animal science and biotechnology, 11, 13-19 (2016)

2. A.D. Alekseev, O.G. Petrova, L.I. Drozdova, Agrarian Bulletin of the Urals, 6 (136), 38-40 (2015)

3. A.D. Alekseev, O.G. Petrova, L.I. Drozdova, Medicus, 3(9), 31-33 (2016)

4. A.D. Alekseev, O.G. Petrova, L.I. Drozdova, Bulletin of OmGAU, 4 (20), 39-44 (2015)

5. A. Balash, G. Batiz, E. Bridle, T. Chaki, III Gombosch, A. Kurtfalvi, Translated from Hungarian 238 (Hungary, Agrota, 1994)

6. M.I. Barashkin, O.G. Petrova, Agrarian Bulletin of the Urals, 3(145), 28-31 (2016)

7. Al.A. Evglevsky, V.N. Skira, E.P. Evglevskaya, N.V. Vanina, I.I. Mikhailova, T.A. Suleymanova, Yu.A. Pereverzeva, Veterinary medicine, 5, 45-48 (2017)

8. Al.A. Evglevsky, E.P. Evglevskaya, I.I. Mikhailova, N.V. Vanina, N.F. Eryzhenskaya, T.A. Suleymanova, Veterinary pathology, 1, 53-58 (2017)

9. A.I. Zolotarev, A.E. Chernitsky, M.I. Retsky, Veterinary medicine, 7, 47-52 (2013)

10. A.S. Krasnoperov, E.M. Maryin, E.A. Zabrodin, M.I. Barashkin, I.M. Milshtein, V.P. Pryanichnikov, N.N. Teterev, BIO, 7(238), 26-33 (2020)

11. S.N. Mager, E.S. Dementieva, Physiology of the immune system 192 (St. Petersburg, Lan, 2014)

12. D. Mail, Immunology. Translated from the English, 586 (M., Logosphere, 2007)

13. N.V. Melnik, A.Ya. Samuylenko, R.N. Melnik, S.A. Grin, V.I. Klyukina, Necrobacteriosis of animals. Treatment and prevention, 279 (Krasnodar, KubGAU, 2018)

14. A.A. Samolovov, S.V. Lopatin, Innovation and food security, 2(2), 76-80 (2017)

15. O.G. Petrova, M.I. Barachkin, L.I. Drozdova, A.D. Alecseev, Advances in agricultural and biological sciences, 3(4), 25-34 (2017) 